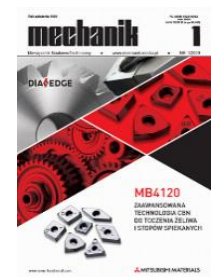

How to cite this article:

Authors: . Maciej Kaczor, Marcin Januszka

Title of article: „Optimization of semi-trailer design as a result of using the MTS road simulator”

Mechanik, No. 1 (2019)

DOI: https://doi.org/10.17814/mechanik.2019.1.10

\title{
Optimization of semi-trailer design as a result of using the MTS road simulator
}

\author{
MACIEJ KACZOR \\ MARCIN JANUSZKA*
}

Mgr inż. Maciej Kaczor, m.kaczor@wielton.com.pl - Politechnika Śląska, Wielton SA, Polska

dr inż. Marcin Januszka, marcin.januszka@polsl.pl, https://orcid.org/0000-0002-0391-8023 - Politechnika Śląska, Wielton SA, Polska

The systematized approach in the process of developing a new technical product should constitute a standard for ensuring high quality, functionality and durability of modern products. This paper presents a methodology used by Wielton company - a manufacturer of trailers and semi-trailers - for the optimization of semi-trailer's construction, supported by a modern test stand - a road simulator included as part of the methodology. As a result of the optimization of the construction with the use of the road simulator, the semi-trailer as a new product for sale is delivered quickly and it is free from any construction defects.

KEYWORDS: road simulator, semi-trailer design, optimization, durability test

The problem of optimization of complex technical measures, which are commercial vehicles, including semi-trailers, is complicated and requires systematization. There are many optimization methods, they are used at various stages of work (from determining the need through the design and construction process, validation tests, etc.) [6]. Usually, at the end of the technical measure development process, prototypes are built and subjected to validation tests at advanced research stands [3, 4]. Only these tests confirm the correctness of the adopted solutions, especially in terms of the criterion of durability.

More and more innovative constructional solutions of commercial vehicles for transport (including trailers and semi-trailers) are emerging, which at the same time must meet a number of requirements, primarily those related to safety, durability and reliability. To eliminate any possible defects, the prototypes of such vehicles are subjected to many tests before they begin mass production and reach customers.

Until recently, manufacturers carried out validation studies only on real roads and in the field. They were expensive and, above all, long-lasting and delayed the launch of products. The solution to this problem are test stands - road simulators that reproduce real-world road conditions with high accuracy.

The use of road simulators during the introduction of vehicles on the market is today popular, but mainly among passenger car manufacturers. With these devices, vehicle manufacturers test: vehicle durability (fatigue tests), quality at the end of production (the so-called first way), driving comfort, volume and dynamics of vehicles.

This paper presents the methodology for optimizing structure in terms of maximizing durability, developed for the research and development department at Wielton, as a result of using an advanced test stand - MTS road simulator $[1,2,5]$.

\section{Construction optimization methodology}

A preliminary concept of methodology for optimizing the construction of new and existing Wielton semitrailers was developed. The aim of the research was to optimize the process of developing a technical measure in terms of shortening the time of implementing new products while guaranteeing high durability and functionality of the products. A scheme has been developed for the implementation of products for sale.

The methodology assumes the following stages of the technical means development process - semi-trailers (fig. 1):

- determination of input data to the process (e.g. requirements, assumptions - functional, economic, strength, durability),

- development of a 3D model of a new technical measure or modification of an existing one, 
- FEM numerical strength analyzes (static and dynamic),

- development of an optimized 3D model based on numerical strength analyzes,

- construction of the first prototype,

- prototype validation tests (using a stand for testing the durability of semi-trailers - MTS road simulator and other test stands, e.g. testing machine, photogrammetric measuring system),

- optimization of the 3D model based on the results of validation tests of the first prototype,

- FEM numerical strength analyzes of components included in the semi-trailer,

- preparation of an approved 3D model of the future technical measure,

- construction of a second prototype,

- validation tests of the second prototype (using the stand for testing the durability of semi-trailers MTS road simulator).

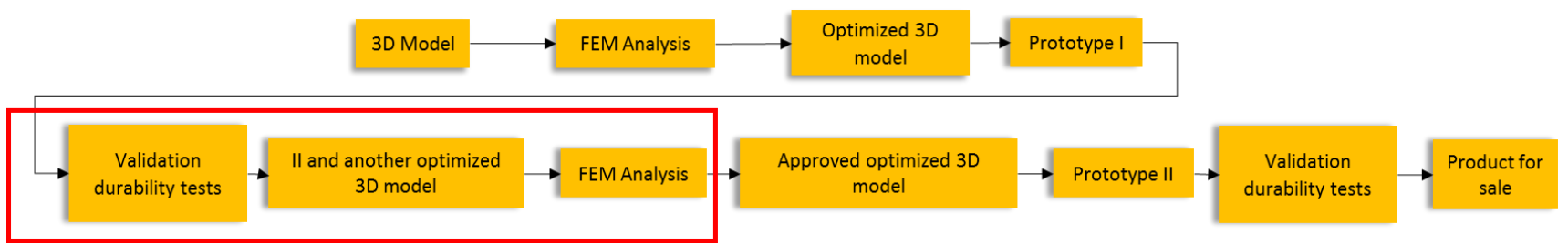

Fig. 1. Stages of developing a new semi-trailer at Wielton

The methodology of construction optimization based on the durability tests of commercial vehicles, especially semi-trailers, assumes the use of methods that will allow limiting structural errors affecting the parameters of the semi-trailer. It includes three stages of the semi-trailer development process: the stage of validating the first prototype using a stand for durability testing (MTS road simulator) and iterative stages of design optimization based on the results of the validation of the first prototype and FEM numerical analyzes. The effect of using this methodology is the elimination of all errors (in assumptions at the level of $98 \%$ of errors) in construction and technology in the technical means being developed, in particular those related to its durability and reliability. These errors concern not only the key parts of the semi-trailer, i.e. the frame and the frame, but also less important components, i.e. fixing of tanks and boxes, ladder, spare wheel basket, extinguisher mounting.

\section{Stand for durability testing}

Wielton, as one of two companies in the industry of semi-trailer and trailer manufacturers, has developed and built in cooperation with MTS Systems / CFM Schiller [5] its own stand - MTS 320 Road Simulator - for conducting durability tests in simulated road and terrain conditions (table). The MTS 320 road simulator allows you to map the movement of the vehicle observed while driving this vehicle on different roads, regardless of the surface quality. The technical capabilities of the station allow with high efficiency to simulate extremely different road conditions - from small vibrations to very strong impacts caused by road potholes.

The stand consists of eight hydraulic cylinders (six for wheels and two for the fifth wheel), controlled by servo valves from the main digital electronic controller, placed on the active damping mass. The cylinders create a vertical force on all tires and the semitrailer saddle plate. This allows you to perform any displacement, speed or acceleration mileage that results from vehicle loads. The control system provides a full set of functional waveforms for testing static and dynamic characteristics.

Configuration of the stand allows testing of uniaxial vehicles with a coupling, two-axle (passenger cars, agricultural trailers) and three-axle (buses, trailers, military vehicles). The active damping mass, exceeding 500 tons, is suspended on 26 pneumatic cushions. Such a construction of the stand makes it possible to limit vibrations to the test field itself, suppressing the vibrations of the tested object, whose mass may exceed 40 tons.

The process of durability tests (fatigue) begins before the semi-trailer is installed on the test stand. In the first phase - preparatory - transducers (sensors) are installed in the vehicle, which allow to record deformations and vibrations of the structure, bellows pressure and axle displacement during the operation of the semi-trailer and save data from EBS. The data is analyzed and processed in such a way that the simulation of the road is most effective. Preparation of the semi-trailer for testing, data collection and durability tests themselves take about two months.

The use of modern measuring cards from the QuantumX family during the test allows the simultaneous registration of dozens of physical quantities that determine the vehicle's behavior during operation. The approach adapts to the vehicle and its purpose. The vehicle's frame includes, among others strain gauges. 
Dozens of strain gauges allow you to reliably assess the state of effort of the frame after its loading, as well as refer to structural analyzes carried out at an earlier stage.

TABLE. Characteristics of roads traversed by the semi-trailer, mapped during a road simulator test

\begin{tabular}{|l|r|r|r|}
\hline \multicolumn{1}{|c|}{ Road type } & Reference mileage, $\mathbf{k m}$ & $\begin{array}{c}\text { Estimated number of } \\
\text { kilometers on the } \\
\text { simulator, km }\end{array}$ & \multicolumn{1}{c|}{ Participation, \% } \\
\hline Local & 487 & 80000 & 20 \\
\hline National & 428 & 200000 & 50 \\
\hline Highway & 268 & 120000 & 30 \\
\hline$\sum$ & 1183 & 400000 & 100 \\
\hline
\end{tabular}

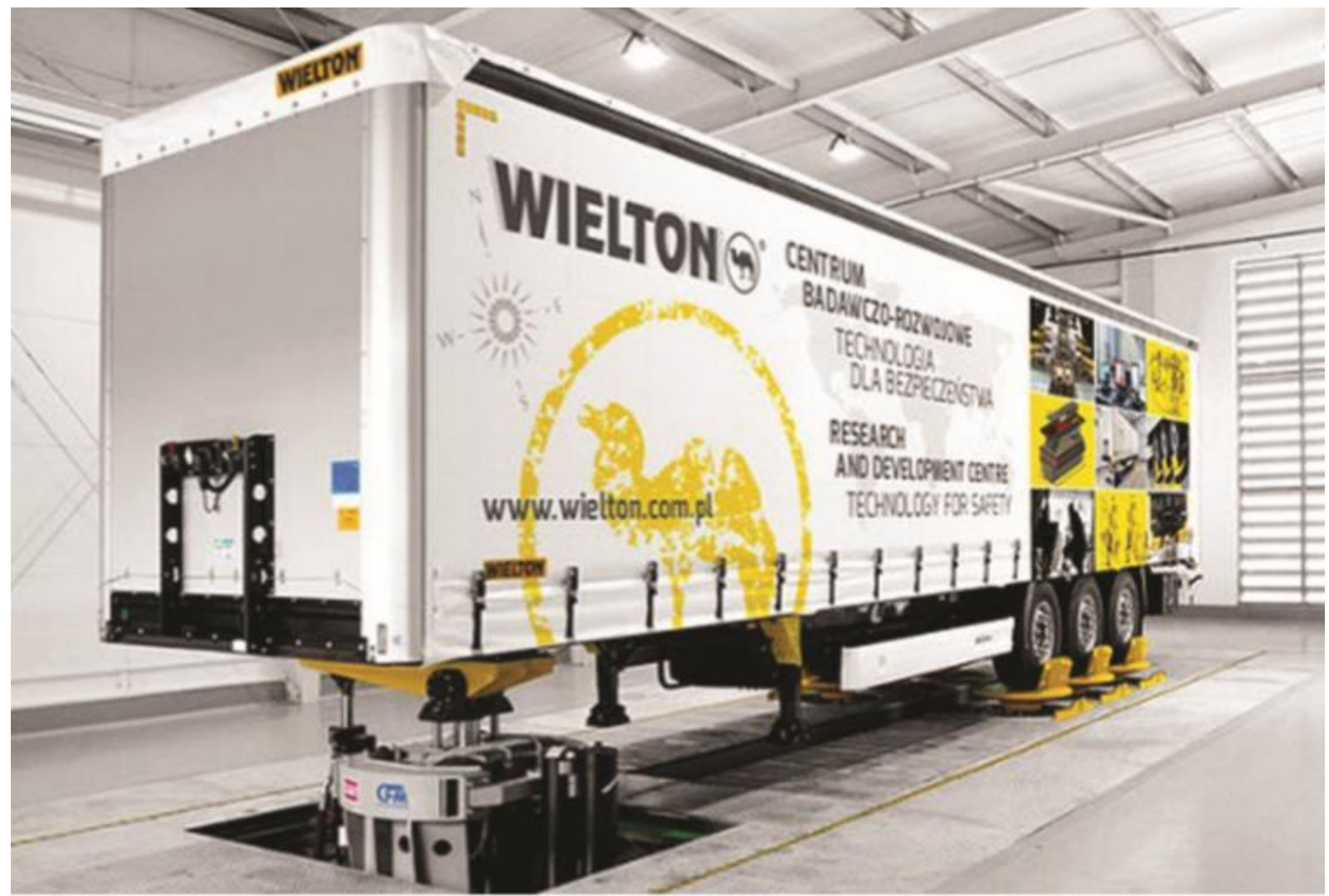

Fig. 2. MTS 320 Road Simulator at the Wielton company during the durability testing of a curtain semitrailer 

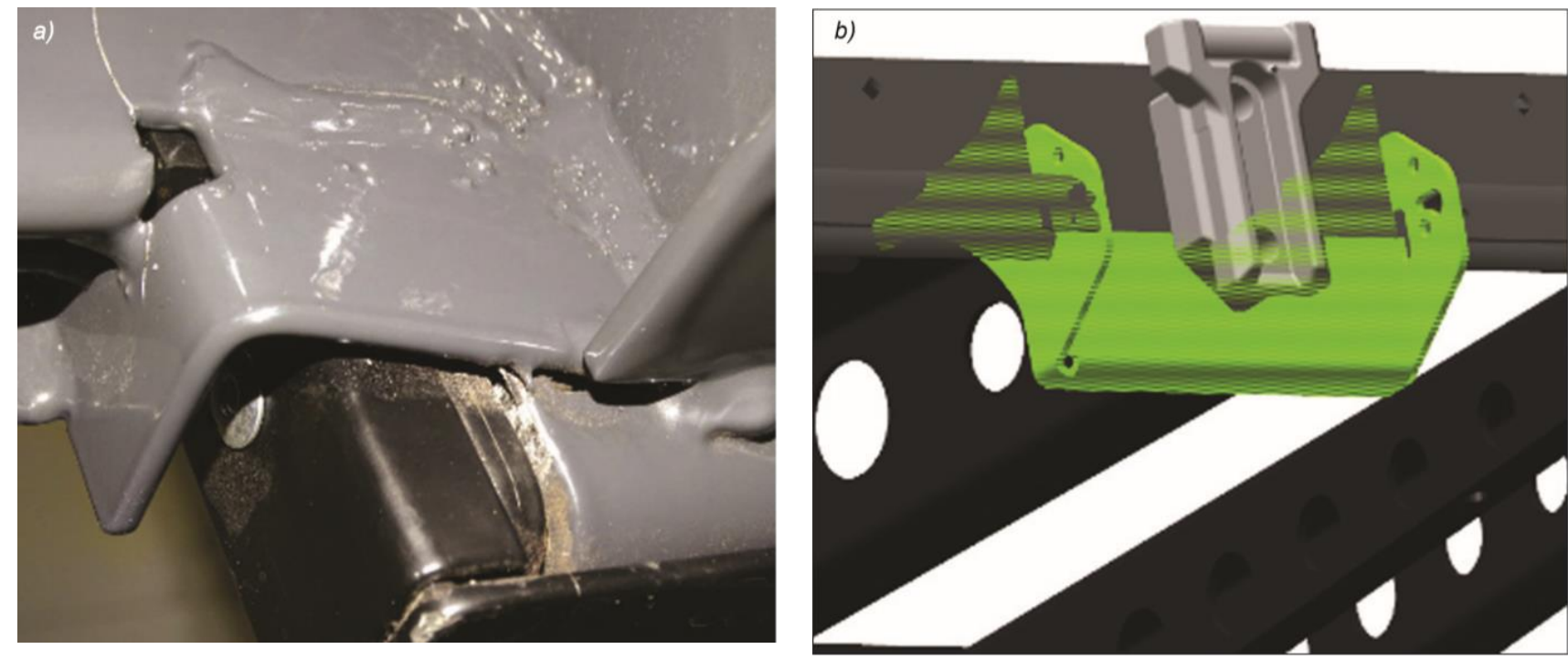

Fig. 3. Strengthening the middle pillar pocket in the curtain semi-trailer as a result of durability test: a) visible damage after the test, b) result of structure optimization in terms of increasing durability

The tests on the stand enable fast vehicle validation and detection of damage that could occur during longterm (many years) of operation. As a result of optimization, the detected damages are eliminated from the structure (fig. 3). It is possible to determine the vehicle's durability over many hundreds of thousands of kilometers during approximately 200-300 hours of operation of the station. Several years of operation of the vehicle is simulated during several months of simulation. The vehicle loads registered during durability tests in various road or terrain conditions are analyzed, and then the vehicle structure is improved on their basis. The result of the work is a lightweight but still very durable construction.

In the era of dynamic introduction of new products to the market, the use of this type of research stands becomes necessary and allows you to gain a competitive advantage.

\section{Summary}

The use of advanced research stands in the process of developing technical means significantly affects their durability. The methodology of structure optimization created for the needs of Wielton company, based on the use of a road simulator, includes fatigue verification of entire vehicles and their individual components (e.g. suspension elements, load securing systems, structural elements of the chassis frame or additional equipment for trailers). In a short period of four weeks, it is possible to simulate the behavior of a semi-trailer corresponding to about four years of real operation.

Methodology used in Wielton and the test stands used in it, which are an important element of validation studies, have many advantages, such as:

- limiting the risk of launching breakthrough solutions on the market;

- faster increase in vehicle competitiveness;

- optimizing vehicle construction;

- reduction of production time and costs, and as a consequence - faster implementation of new products;

- reducing the number of complaints and service costs;

- increasing the value and prestige of the Wielton brand.

Customers expect that in a short time they will receive a reliable, tested product that meets their needs. The adoption of a systematic approach to the development of new construction solutions and their optimization as a result of the use of modern, mechatronic research stands meet these expectations. Therefore, it should be assumed that in the future this type of approach to the development of new products will be increasingly common not only among large producers.

Research financed by the Ministry of Science and Higher Education on the basis of contract No. 12/DW/2017/01/1 of 07.11.2017 in the amount of PLN 4433520.00. 


\section{REFERENCES}

[1] Azrulhisham E., Asri Y.M., Dzuraidah A.W., Nik Abdullah N.M., Che Hassan C.H., Shahrom A. "Application of road simulator service loads in automotive component durability assessment". The Open Industrial \& Manufacturing Engineering Journal. 4 (2011): 1-7.

[2] Dilip M., Gangwani G. "Design optimization of truck body". IJIRST - International Journal for Innovative Research in Science \& Technology. 3, 2 (2016): 383-385.

[3] Dodds C., Plummer A. "Laboratory road simulation for full vehicle testing: a review". SAE Technical Paper 2001-26-0047 (2001).

[4] Medepalli S., Rao R. "Prediction of road loads for fatigue design-sensitivity study". International Journal of Vehicle Design. 23, 1-2 (2000): 161-175.

[5] MTS. Model 320 Tire-Coupled Road Simulators, https://www.mts.com/cs/groups/public/documents/library/dev_002219.pdf, (access: 25.11. 2018 ).

[6] You S., Joo S. "Virtual testing and correlation with spindle coupled full vehicle testing system". SAE Technical Paper 2006-01-0993 (2006). 